\title{
Monsoon reconstruction in subtropical Asia from oxygen isotope ratios of tree-ring cellulose
}

\author{
Masaki Sano, C. Xu and T. Nakatsuka \\ Graduate school of Environmental Studies, Nagoya University, Japan; sano.masaki@b.mbox.nagoya-u.ac.jp
}

\begin{abstract}
Tree-ring records reveal that climatic sensitivity of cellulose $\delta^{18} \mathrm{O}$ can be higher than that of ring width, that summer monsoon in the Himalayas has weakened over the last two centuries, and that El Niño-Southern Oscillation significantly affects the hydroclimate of Southeast Asia.
\end{abstract}

$T^{n}$ he impact of hydrologic regime shifts in the Asian Monsoon under changing global climate is significant, since the intensity of monsoon directly affects the agricultural production of the most densely populated regions in the world. Proxy climate records dating back to the pre-instrumental era are therefore essential for evaluating the roles of natural variability and anthropogenic impact on the Asian Monsoon system. Tree rings have often been used to reconstruct past climate variations with annual resolution, and extensive networks of tree-ring chronologies have been developed in North America and Europe. Unlike in higher latitudes, relatively few tree-ring chronologies were produced for tropical and subtropical Asia, since the lack of climatic seasonality hinders annual ring formation of most tree species in these regions. However, over the last couple of decades dendrochronologists have found increasing success in the low latitudes of Asia by selecting regions with more pronounced temperature or precipitation seasonality.

\section{Tree-ring $\delta^{18} \mathrm{O}$ as a hydrologic proxy}

A major recent advance has been the hydroclimatic reconstructions from rare and long-lived Fujian Cypress (Fokienia hodginsii) growing in Vietnam (Buckley et al. 2010; Sano et al. 2009). These records based on ring width measurement revealed that the region experienced decadal-scale droughts in the past, which have no analog in the instrumental period. Interestingly, these exceptional droughts coincided with periods of social unrest (Buckley et al. 2010). In addition to this progress, other recent studies indicated that oxygen isotope ratios of tree-ring cellulose might help improve our understanding of monsoon activity (Sano et al. 2012a,b ; Xu et al. 2011). In this brief note, we show some advantages of using tree-ring $\delta^{18} \mathrm{O}$ rather than ring width and wood density traditionally utilized in dendroclimatolgy.

It is well known that tree-ring width and wood density are controlled not only by climate but also by endogenous disturbance pulses, such as competition with neighboring trees. To reduce such disturbances, climatically sensitive trees are sampled predominantly at the species ecological boundaries, such as near arid or cold forest limits. This spatial limitation can be overcome by using oxygen isotope ratios, since the isotopic ratio in the wood is not significantly affected by ecophysiological processes. Tree-ring $\delta^{18} \mathrm{O}$ is theoretically controlled by two climatic factors, $\delta^{18} \mathrm{O}$ of the source water and relative humidity (e.g. Robertson et al. 2001; Saurer et al. 1997), both of which are closely related to monsoon activity in South and Southeast Asia. Our preliminary analyses using samples from the Himalayas (Sano et al. 2010) and Laos (Xu et al. 2011) clearly show that treering $\delta^{18} \mathrm{O}$ is more strongly correlated with precipitation, relative humidity, temperature and Palmer Drought Severity Index (PDSI) than is ring width or wood density. PDSI is a drought metric based upon a water balance model. Positive and negative values of the PDSI correspond respectively to wet and dry conditions (Palmer 1965; Dai et al. 2004).

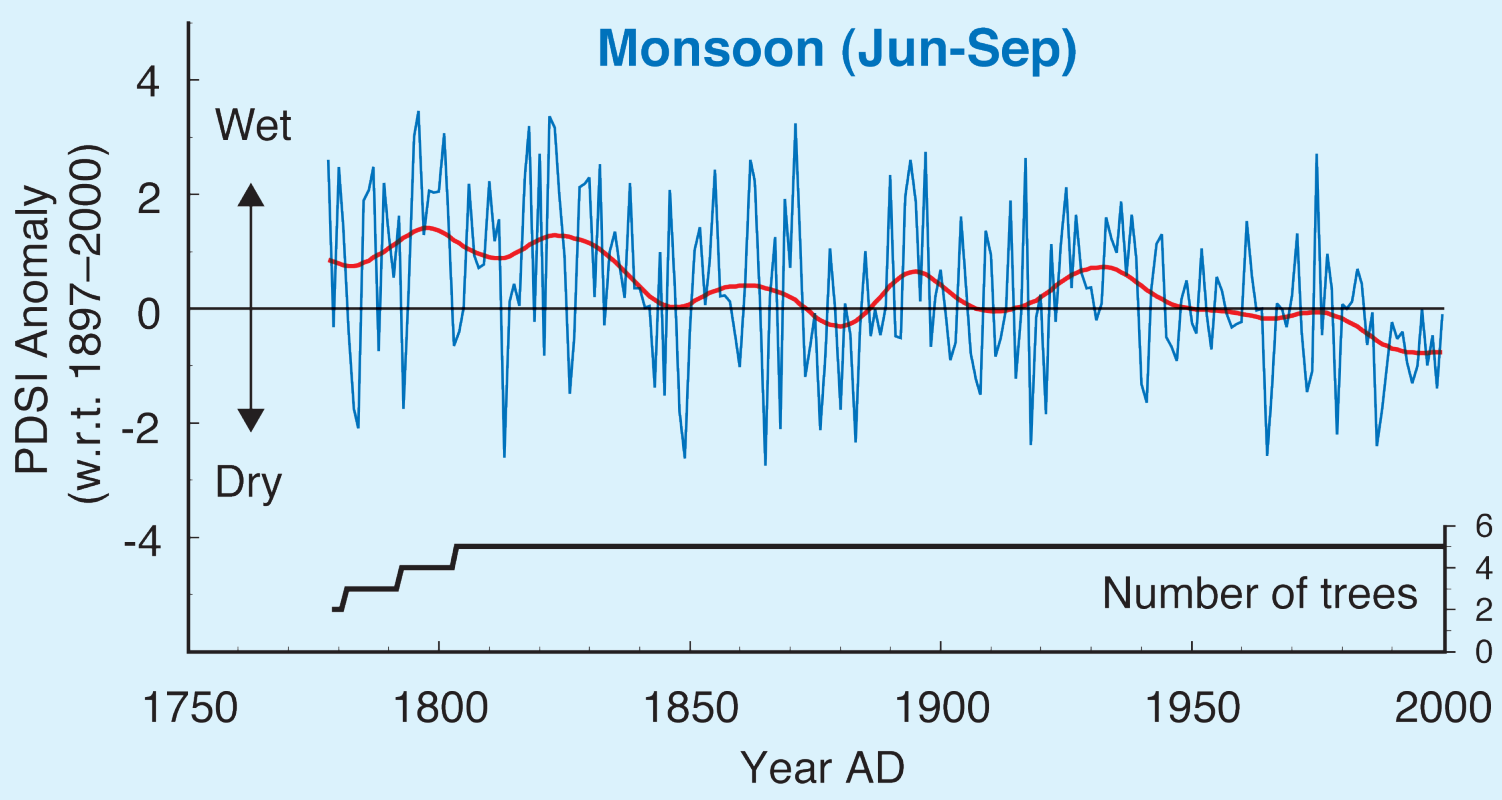

Figure 1: Reconstructed June-September PDSI from tree-ring $\delta^{18} \mathrm{O}$ in the Nepal Himalayas. The thick curve represents a 30-year cubic spline. Figure modified from Sano et al. (2012a). 


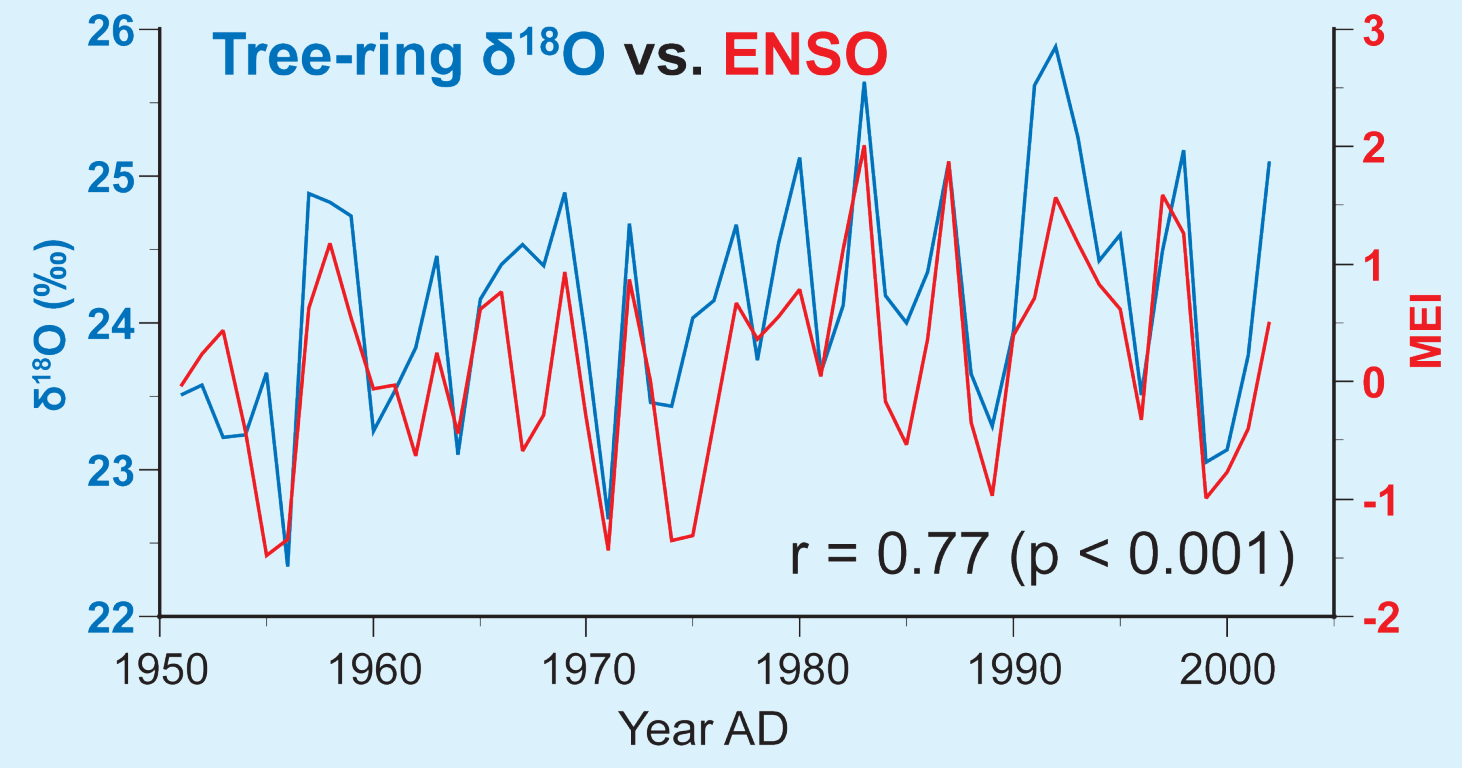

Figure 2: Comparison of inter-annual variations in tree-ring $\delta^{18} \mathrm{O}$ from Laos and the Multivariate ENSO index (MEI) for the period of 1951-2002. Figure modified from Xu et al. (2011).

\section{Evidence of weakening monsoon over the Himalayas and Tibet for the last two centuries}

Tree-ring $\delta^{18} \mathrm{O}$ from the Nepal Himalayas accounts for $34 \%$ of the inter-annual variability of the PDSI in the monsoon season (July-September), and clearly shows a decreasing trend of precipitation/moisture over the last two centuries (Fig. 1). Evidence for a decrease in summer monsoon rainfall was also found in $\delta^{18} \mathrm{O}$ of tree rings from Tibet (Grießinger et al. 2011), $\delta D$ of an ice core from Mt. Everest (Kaspari et al. 2007), snow accumulation of an ice core from Dasuopu, Tibet (Zhao and Moore 2006), and varve thickness of lake sediments in Tibet (Chu et al. 2011). The overall trends toward arid conditions indicate that summer monsoon has weakened across wide areas of the Himalayas and Tibet for at least the last couple of centuries.

Our reconstructed PDSI shows significant correlations with sea surface temperatures in the tropical Pacific and Indian Ocean, suggesting that the tropical oceans play a role in modulating hydroclimate in the Nepal Himalayas. A simulation model forced by observed sea surface temperature (SST) data reveals that a weakening trend of monsoon precipitation found in northern India and the eastern Tibetan Plateau over the latter half of the $20^{\text {th }}$ century is deducible from the atmosphere's response to an increase in SSTs over the tropical Pacific and Indian Ocean (Zhou et al. 2008). Therefore, the consistent warming found in reconstruction of tropical SSTS over the last two centuries (Wilson et al. 2006) might be responsible for the weakening monsoon in the Himalayas. In contrast, other proxy records from lower altitudes indicate a strengthening of the monsoon winds (Anderson et al. 2002) and precipitation (Wang et al. 2005). The increased north-south difference of monsoon activity is likely induced by a southward shift in the overall position of the monsoon trough.

\section{Links between ENSO and tree-ring $\delta{ }^{18} \mathrm{O}$ records from Southeast Asia}

In contrast to ring-width-based reconstructions from the Himalayas and Tibet, those from Southeast Asia are rare, since most trees grow in relatively warm and wet environments. To overcome this limitation, isotopic analyses have been conducted on samples from four cypress trees from Laos for the past 52 years (1951-2002). It turned out that contrary to the tree-ring widths data (Xu et al. 2011), the $\delta^{18} \mathrm{O}$ time series of the trees are significantly correlated with each other. Also, the $\delta^{18} \mathrm{O}$ chronology built from the four trees shows significant correlation with temperature $(r=0.64, p<0.001)$, precipitation $(r=-0.34, p<0.05)$ and PDSI $(r=-0.66, p<0.001)$ in the monsoon season. In contrast, no significant correlation was found between any climatic variables and a ring-width chronology based on 15 trees, which includes the four trees utilized for the isotope measurement. Finally, the $\delta^{18} \mathrm{O}$ chronology is strongly correlated with ENSO-related indices, particularly with the Multivariate ENSO Index (MEl; Wolter and Timlin 2011) for the last 52 years (Fig. 2). To further explore the potential of isotope dendroclimatology, six more cypress trees from Vietnam have been subjected to $\delta^{18} \mathrm{O}$ analyses. Surprisingly, the $\delta^{18} \mathrm{O}$ chronology from Vietnam is closely correlated to that from Laos (Sano et al. 2012b), even though these sampling sites are around $150 \mathrm{~km}$ away from each other. Moreover, the teleconnected relationships between the $\delta^{18} \mathrm{O}$ chronology and ENSO-related indices are stable over the 135-year period of available instrumental data.

Over the last decade, considerable effort has been devoted to reconstruct ENSO variability using tree rings and other proxy records that originate mainly from North America and the topical Pacific (e.g. D'Arrigo et al. 2005; Mann et al. 2000; Wilson et al. 2010). Although these records agree well during the twentieth century, there is relatively little agreement before this time. Wilson et al. (2010) point out that the teleconnected relationship between the tropical central/eastern Pacific and regions where proxy records are located does not seem to be stable. Since none of the previously published reconstructions of ENSO variability include data from mainland Southeast Asia, tree-ring $\delta^{18} \mathrm{O}$ is of great use to independently reconstruct ENSO, and to explore the spatial influence of ENSO before the instrumental period.

\section{Selected references}

Full reference list online under:

http://www.pages-igbp.org/products/newsletters/ref2012_2.pdf

Buckley BM et al. (2010) PNAS 107: 6748-6752

Sano M, Ramesh R, Sheshshayee MS, Sukumar R (2012a) The Holocene 22(7): 809-817

Sano M, Xu C and Nakatsuka T (2012b) Journal of Geophysical Research 117, doi: 10.1029/2012JD017749

Wilson R et al. (2010) Journal of Quaternary Science 25(1): 62-78

Xu C, Sano M, Nakatsuka T (2011) Journal of Geophysical Research 116 doi: 10.1029/2011JD016694 